\title{
Phreatic eruptions and deformation of loto Island (Iwo-jima), Japan, triggered by deep magma injection
}

\author{
Hideki Ueda*, Masashi Nagai and Toshikazu Tanada
}

\begin{abstract}
On loto Island (Iwo-jima), 44 phreatic eruptions have been recorded since 1889, when people began to settle there. Four of these eruptions, after the beginning of continuous observation by seismometers in 1976, were accompanied by intense seismic activity and rapid crustal deformation beforehand. Other eruptions on loto were without obvious crustal activities. In this paper, we discuss the mechanisms of phreatic eruptions on loto. Regular geodetic surveys and continuous GNSS observations show that loto intermittently uplifts at an abnormally high rate. All of the four eruptions accompanied by the precursors took place during intermittent uplifts. The crustal deformation before and after one of these eruptions revealed that a sill-like deformation source in the shallow part of Motoyama rapidly inflated before and deflated after the beginning of the eruption. From the results of a seismic array and a borehole survey, it is estimated that there is a layer of lava at a depth of about 100-200 m, and there is a tuff layer about 200-500 m beneath it. The eruptions accompanied by the precursors probably occurred due to abrupt boiling of hot water in hydrothermal reservoirs in the tuff layer, sealed by the lava layer and triggered by intermittent uplift. For the eruptions without precursors, the hydrothermal systems are weakly sealed by clay or probably occurred on the same principle as a geyser because phreatic eruptions had occurred beforehand and hydrostatic pressure is applied to the hydrothermal reservoirs.
\end{abstract}

Keywords: Phreatic eruption, Caldera, Earthquake, Crustal deformation, Precursor, Transient deformation

\section{Introduction}

Ioto Island (Iwo-jima) is a volcanic island located about $1200 \mathrm{~km}$ south of Tokyo, Japan (Fig. 1). It is one of the volcanoes of the Izu-Bonin-Mariana island arc accompanying the subduction of the Pacific plate beneath the Philippine Sea plate. The island is about $8 \mathrm{~km} \times 4 \mathrm{~km}$ in size. Bathymetry shows that Ioto is the summit of a stratovolcano with a height of about $2000 \mathrm{~m}$ from the ocean floor and a width of about $40 \mathrm{~km}$, and rock reefs at sea showing ring-shaped topography suggest there is a caldera rim with a diameter of about $10 \mathrm{~km}$ at the top of the mountain (Fig. 1b). There are three main topographic features on Ioto: Motoyama, Suribachiyama and Chidorigahara. Motoyama, with an altitude of about $110 \mathrm{~m}$, on

\footnotetext{
*Correspondence: ueda@bosai.go.jp

National Research Institute for Earth Science and Disaster Resilience, Tennôdai 3-1, Tsukuba-shi, Ibaraki-ken 305-0006, Japan
}

the east side of Ioto is a resurgent dome formed at the central part of the caldera (Newhall and Dzurisin 1988). Suribachiyama, with an altitude of about $170 \mathrm{~m}$, is a monticule on the southwest of Ioto. Motoyama and Suribachiyama are connected by a wedge-shaped sandbar called Chidorigahara.

Motoyama is covered with pyroclastic flow deposits and lava flows from a large-scale magmatic eruption (the Motoyama eruption) dated to $2.7 \mathrm{cal} \mathrm{kBP}$ (Nagai and Kobayashi 2015). A borehole survey (depth $150 \mathrm{~m}$ ) was conducted in the central part of Motoyama, and it provides the only result that has been published (Ossaka et al. 1985). The drilling core shows alternating layers consisting of lava flows and pyroclastic rocks. Lava layers found on the east coast (Nagai and Kobayashi 2015) at depths of 24-97.9 and 106.6-130.5 m were presumed to be Motoyama lava and Hanareiwa lava, respectively. Hanareiwa lava was erupted before the Motoyama 


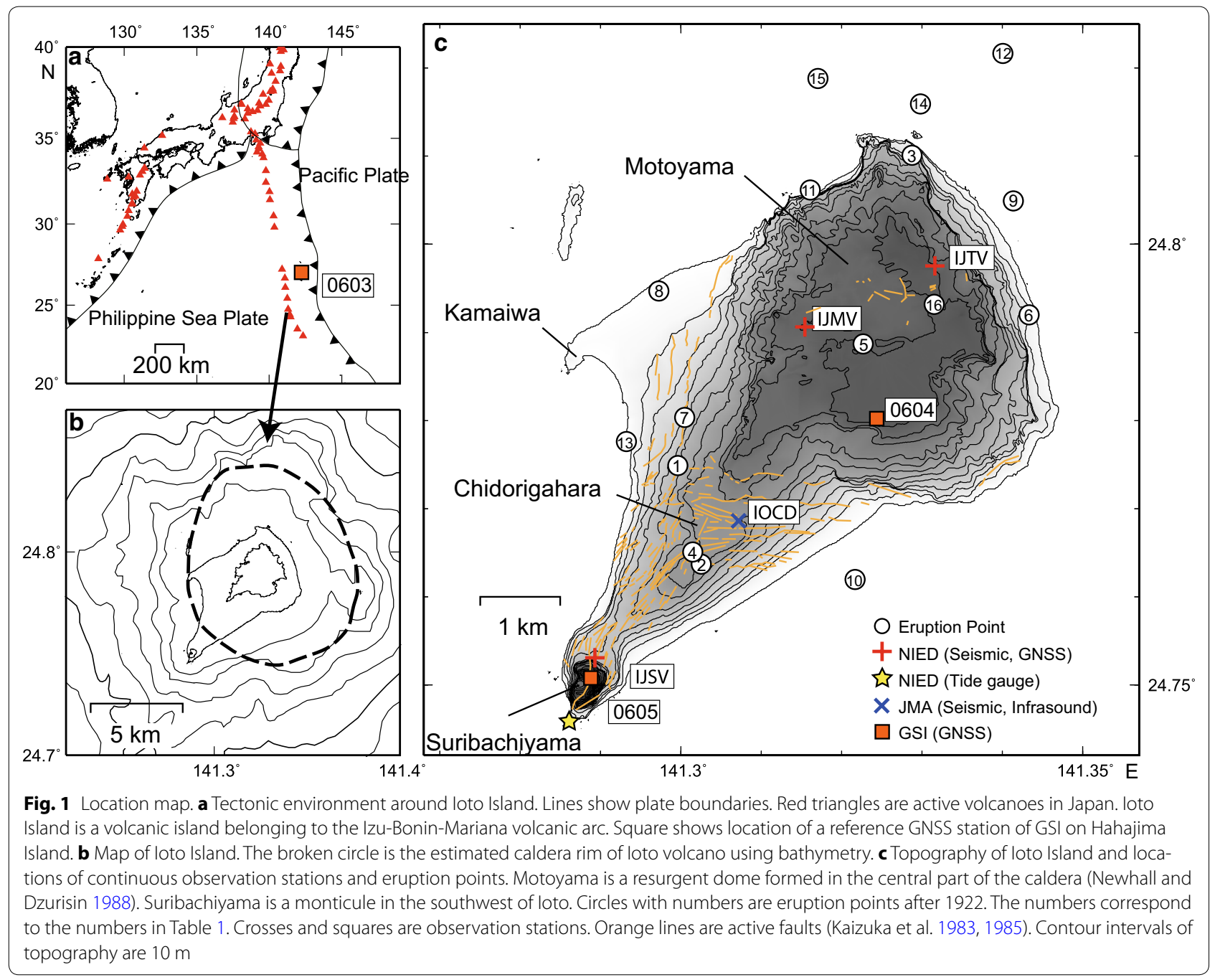

eruption, but the eruption time is unknown. It was estimated that there was already a caldera rim during the Motoyama eruption but that there had been a large-scale eruption forming a caldera even before $2.7 \mathrm{cal} \mathrm{kBP}$. Since then, Suribachiyama has experienced at least three magmatic eruptions. Nagai and Kobayashi (2015) suggested that the last eruption was earlier than 1779 as the current shape of Suribachiyama resembles the shape of the 1779 picture (King 1785).

It is known that a large-scale uplift has continued in Ioto for centuries. The ${ }^{14} \mathrm{C}$ age of corals collected at the central part of Motoyama at an altitude of about $110 \mathrm{~m}$ was estimated at $500-800$ years, and the average uplift rate is presumed to be $15-20 \mathrm{~cm}$ per year (Kaizuka et al. 1983, 1985). The distribution of coastal terraces shows that intermittent uplift continues. Geodetic surveys and aerial photography from 1952 and 1968 indicate that Motoyama uplifted by about $9 \mathrm{~m}$ during those 16 years (Tsuji et al. 1969). Kamaiwa, sticking out to the northwest, was a reef (Fig. 1c), but in 1969 it was connected to the mainland (Oyagi and Inokuchi 1985). According to surveys periodically conducted since 1976, Motoyama uplifted by about $0.5 \mathrm{~m}$ and Chidorigahara uplifted by about $4 \mathrm{~m}$ from 1977 to 2002 (Ukawa et al. 2006). Ukawa et al. (2006) showed that the crustal deformation is a superposition of the episodic uplift of the whole island and continuous deformation of Motoyama. This continuous deformation is due to the contraction of the central part of Motoyama and the uplift of the surrounding area. They interpreted the episodic uplift of the whole island and the continuous deformation as a deep magma intrusion and a long-term movement of volcanic fluid, respectively. Active faults are predominantly distributed in Chidorigahara (orange lines in Fig. 1c) due to the severe uplift of Motoyama (Kaizuka et al. 1983, 1985). Seismic activity is also very pronounced due to intense crustal movement. The earthquakes have a maximum magnitude of M3 with the majority of them occurring at depths shallower than $3 \mathrm{~km}$ BSL. 
Ioto has very high geothermal activity throughout the island, with phreatic eruptions occurring frequently in craters and fumarolic areas. Since settlement began in 1889, 44 eruptions were recorded up until August 2017 (Table 1). The eruptions listed in Table 1 are those witnessed by local residents, along with observed volcanic tremors by seismometers and confirmed eruptions by field surveys. In addition, there are instances where discolored water spotted on the sea surface led to the assumption of eruptions. In an eruption that occurred in Chidorigahara on March 28, 1957 (No. 4 in Fig. 1c), a plume of about $60-90 \mathrm{~m}$ in height rose and a crater with a diameter of $30 \mathrm{~m}$ was formed (Corwin and Foster 1959). This is a typical phreatic eruption, blowing out steam and sand. At least two eruptions occurred at the Asodai sinkhole from November 28-29, 1982 (No. 7 in Fig. 1c), and volcanic earthquakes observed from August 25-30 reached 1492 in number, and many fault movements was detected (Kumagai et al. 1985). Recently, eruptions have taken place at Million dollar hole during 2012-2013 (No. 1 in Fig. 1c) and Idogahama (No. 8 in Fig. 1c) and Kitanohana (No. 3 in Fig. 1c) in 2015 (Japan Metrological Agency 2012, 2013a, b, c, d, 2015a, b, c). Juvenile material was not detected in either eruption; they were phreatic eruptions. The eruption points 9, 10, 12, 14 and 15 in Fig. 1c are located in the ocean area. In 1994, white smoke and muddy water erupted and a crater was formed at a rock reef by eruption point 9 . Also, several tens of meters of plume had been observed at 10, and a volcanic tremor was observed when an eruption took place at 12 . They were definitely phreatic eruptions. However, at points 14 and 15 in 2013, only discolored waters were confirmed.

Here, we aim to investigate the mechanisms of the phreatic eruptions of Ioto. Some phreatic eruptions have been accompanied by clear precursors. However, eruptions without precursors have also been reported. Phreatic eruptions and related activities such as earthquakes, deformation and fumaroles on the ground are considered to be related with hydrothermal reservoirs of shallow depths (e.g., Kaneshima et al. 1996). We will clarify the relationship between phreatic eruptions and hydrothermal reservoirs in Ioto with seismic and crustal deformation data. Although the scale of phreatic eruptions is small in Ioto, they are frequent, occurring everywhere on the island. Elucidation of the regularity and mechanisms of phreatic eruptions helps to reduce the risk to residents on the island.
Table 1 Eruption list

\begin{tabular}{|c|c|c|c|c|}
\hline No. & Date & $\begin{array}{l}\text { Location } \\
\text { (Fig. 1c) }\end{array}$ & Precursor & References \\
\hline 1 & 1889 or 90 & $1 ?$ & $?$ & Ogawa (1912) \\
\hline 2 & Jul. 1922 & 1 & $?$ & Toyoshima (1932) \\
\hline 3 & 1935 & 2 & $?$ & Morimoto et al. (1968) \\
\hline 4 & Dec. 1944 & 3 & $?$ & Kumagai (1985) \\
\hline 5 & Mar. 28, 1957 & 4 & $?$ & Corwin and Foster (1959) \\
\hline 6 & Dec. 23, 1967 & 1 & $?$ & Morimoto et al. (1968) \\
\hline 7 & Jun. 20, 1968 & 5 & $?$ & Morimoto et al. (1968) \\
\hline 8 & Jan. 12, 1969 & 1 & $?$ & Kumagai (1985) \\
\hline 9 & Nov. or Dec. 1969 & 6 & $?$ & Kumagai (1985) \\
\hline 10 & Nov. 1975 & 3 & $?$ & Kumagai (1985) \\
\hline 11 & Jan. 1976 & 7 & $?$ & Kumagai (1985) \\
\hline 12 & Dec. 11, 1978 & 7 & No & Kumagai (1985) \\
\hline 13 & Mar. 13, 1980 & 3 & No & Kumagai (1985) \\
\hline 14 & Mar. 9-10, 1982 & 8 & No & Kumagai (1985) \\
\hline 15 & Nov. 28-29, 1982 & 7 & Yes & Kumagai (1985) \\
\hline 16 & Dec. 1982 & 7 & No & Kumagai 1985 \\
\hline 17 & Aug. 22, 1994 & 9 & No & Ukawa et al. (2002) \\
\hline 18 & Sep. 10, 1999 & 7 & No & JMA (2013a) \\
\hline 19 & Sep. 21-22, 2001 & 10 & Yes & Ukawa et al. (2002) \\
\hline 20 & Oct. 19-23, 2001 & 8 & No & Ukawa et al (2002) \\
\hline 21 & Oct. 7, 2002 & 7 & No & JMA (2013a) \\
\hline 22 & Nov. 8, 2002 & 7 & No & JMA (2013a) \\
\hline 23 & Apr. 28, 2004 & 9 & No & JMA (2013a) \\
\hline 24 & Jun. 6-8, 2004 & 7 & No & JMA (2013a) \\
\hline 25 & Dec. 19-20, 2007 & 7 & No & JMA (2013a) \\
\hline 26 & Feb. 2012 & 1 & No & JMA (2013a) \\
\hline 27 & Mar. 7, 2012 & 1 & No & JMA (2013a) \\
\hline 28 & Apr. 5-6, 2012 & 1 & No & JMA (2013a) \\
\hline 29 & Apr. 28, 2012 & 11 & Yes & JMA (2013a) \\
\hline 30 & Apr. 29-30, 2012 & 12 & No & JMA (2013a) \\
\hline 31 & Jul. 9, 2012 & 1 & No & JMA (2013a) \\
\hline 32 & Sep. 72012 & 13 & No & JMA (2013a) \\
\hline 33 & Dec. 1, 2012 & 1 & No & JMA (2012) \\
\hline 34 & Feb. 17-18, 2013 & 1 & No & JMA (2013b) \\
\hline 35 & Mar. 5-6, 2013 & 1 & No & JMA (2013c) \\
\hline 36 & Apr. 11, 2013 & 1 & No & JMA (2013d) \\
\hline $37^{a}$ & Aug. 21, 2013 & 14 & No & JMA (2013a) \\
\hline $38^{\mathrm{a}}$ & Aug 28-30, 2013 & 15 & No & JMA (2013e) \\
\hline 39 & Dec. 16, 2014 & 16 & No & JMA (2014) \\
\hline 40 & May 22-24, 2015 & 8 & No & JMA (2015a) \\
\hline 41 & Jun. 20, 2015 & 8 & No & JMA (2015b) \\
\hline 42 & Aug. 7, 2015 & 3 & Yes & JMA (2015c) \\
\hline 43 & Aug. 25-26, 2015 & 1 & No & JMA (2015c) \\
\hline 44 & Sep. 1, 2016 & 7 & No & JMA (2015d) \\
\hline
\end{tabular}

a Only discolored waters were confirmed 

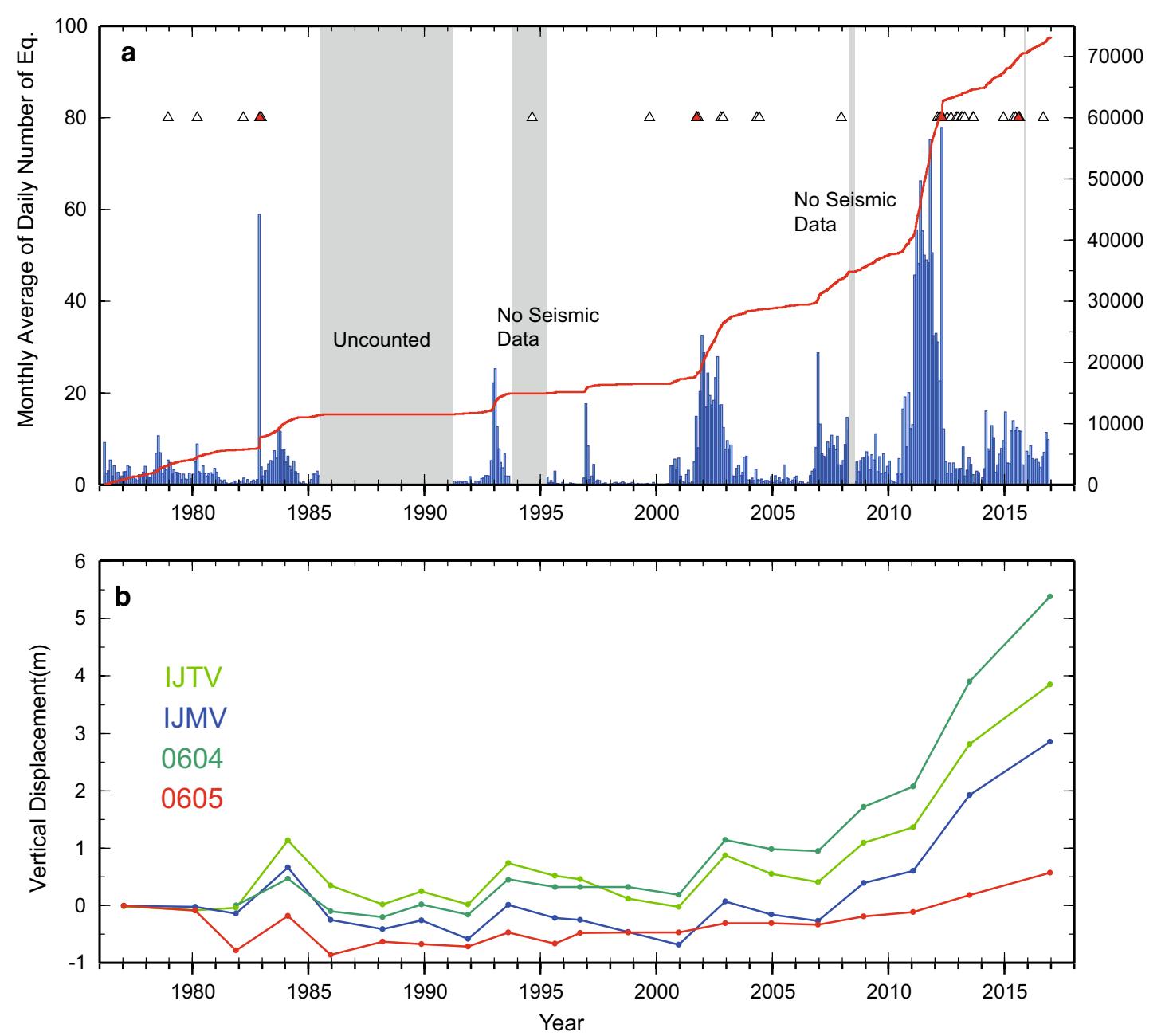

Fig. 2 A comparison between earthquake activity and vertical movement of loto after 1977. a Monthly average of daily number of earthquakes counted at Motoyama. The numbers are counted at seismic stations of Japan Ministry of Defense around 0604 station of GSI before 1986 and at IJMV after 1992. The red curve shows the cumulative number of earthquakes. The red triangles and white triangles denote occurrence times of phreatic eruptions with and without precursors, respectively. b Vertical movement by campaign leveling and GPS surveys after 1977 at survey points near observation points where GNSS continuous observation is carried out. In the leveling survey up until 1995, average sea level as measured by the tide level gauge was taken as the reference height

\section{Observations}

Volcanic unrest of Ioto is characterized by intense seismic activity and rapid uplift. In order to investigate the relationship between the occurrence of phreatic eruption, seismic activity and uplift, we first looked at observations of the earthquakes and crustal deformation of Ioto. Figure 1c shows the distribution of continuous observation stations used in this study. National Research Institute for Earth Science and Disaster Resilience (NIED) has conducted continuous observation of seismometers and GNSS at three observation points. Earthquakes have been observed since 1982, and continuous observation by GNSS started in 2003. Japan Meteorological Agency (JMA) has been observing earthquakes and infrasound at one point since 2011. Geospatial Information Authority of Japan (GSI) has been conducting continuous observation of GNSS at two points since 1997. Japan Ministry of Defense had been conducting continuous observation of a seismometer from March 1976 around 0604 station of GSI, but it was discontinued in the 1990s. NIED also conducts periodic surveys every 2 years, as will be described later in this paper.

Figure 2a shows the monthly average number of daily earthquakes occurring on the island observed at Motoyama. From March 1976 to June 1985, it was the observation point of Japan Ministry of Defense, and after that, the number of earthquakes counted came from records at IJMV. This number of earthquakes was chosen 

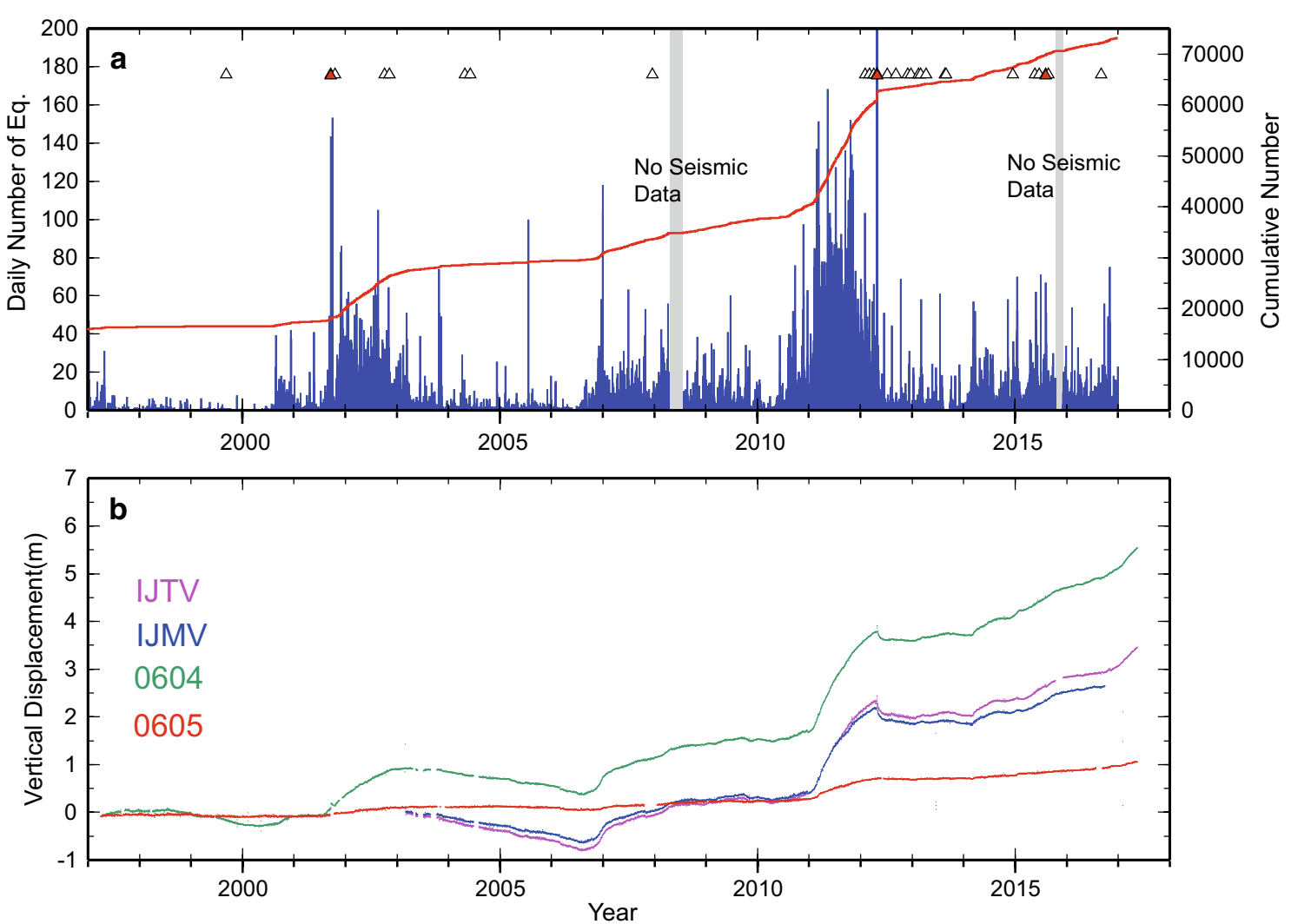

Fig. 3 A comparison between earthquake activity and vertical movement of loto after 1997. a Daily number of earthquakes counted at IJMV. The red curve shows the cumulative number of earthquakes. The red triangles and white triangles denote occurrence times of phreatic eruptions with and without precursors, respectively. $\mathbf{b}$ Vertical movement by daily solutions of continuous GNSS observation after 1997 at the continuous stations

by counting what is supposed to have occurred inside the island. Since 2003, we have determined the hypocenter and that the depth of $95 \%$ of the earthquakes that occurred inside the island is less than $3 \mathrm{~km}$. Although it was not counted from June 1985 until March 1991, it was reported that earthquake activity was low (NIED 1992).

We will compare this seismic activity with the crustal deformation after 1976 (Ukawa et al. 2006). NIED conducted leveling and trilateration 11 times every other year from 1976 to 1995. Furthermore, GPS surveys were conducted 10 times every 2 years from 1996 to 2016. Results until 2002 are summarized in Ukawa et al. (2006). Figure $2 \mathrm{~b}$ shows vertical movement obtained by leveling and GPS from 1977 at the survey point within $10 \mathrm{~m}$ of the observation point where GNSS continuous observation was carried out. In the leveling survey until 1995, the average sea level measured by the tide level gauge was taken as the reference height (the location of tide level gauge is shown by a star in Fig. 1c). Temporary tide level observation from 1977 to 1980 and a tidal level gauge of continuous observation from 1980 to 1995 were employed to monitor the tide level, and the results were used as the reference height for the levelling surveys. Since we do not have tide level data for 1976, the survey result is not included in Fig. 2b.

After 1977, the three observation points of Motoyama showed definite periods of uplift approximately every 10 years (1982-1984, 1991-1993, 2000-2002, 20062016), and subsided in the intervening periods. This intermittent uplift is a common crustal deformation of caldera volcanoes, as exemplified at Campi Flegrei (Bellucci et al. 2006), Yellowstone (Chang et al. 2007), and Rabaul (Robertson and Kilburn 2016) calderas. The intermittent uplift of Ioto is interpreted as a consequence of magma injections into a deep magma reservoir (Ukawa et al. 2006). A comparison of the number of earthquakes and vertical movement in Fig. 2a shows that the number of earthquakes is also relatively large during intermittent uplifts. Figure 3 shows a more detailed view of the relationship between earthquakes and uplift by GNSS, which allows for a higher time resolution. We compared the vertical displacement after the start of GNSS continuous observation from 1997 with the number of daily earthquakes. Using GNSS data of NIED and GSI observation 

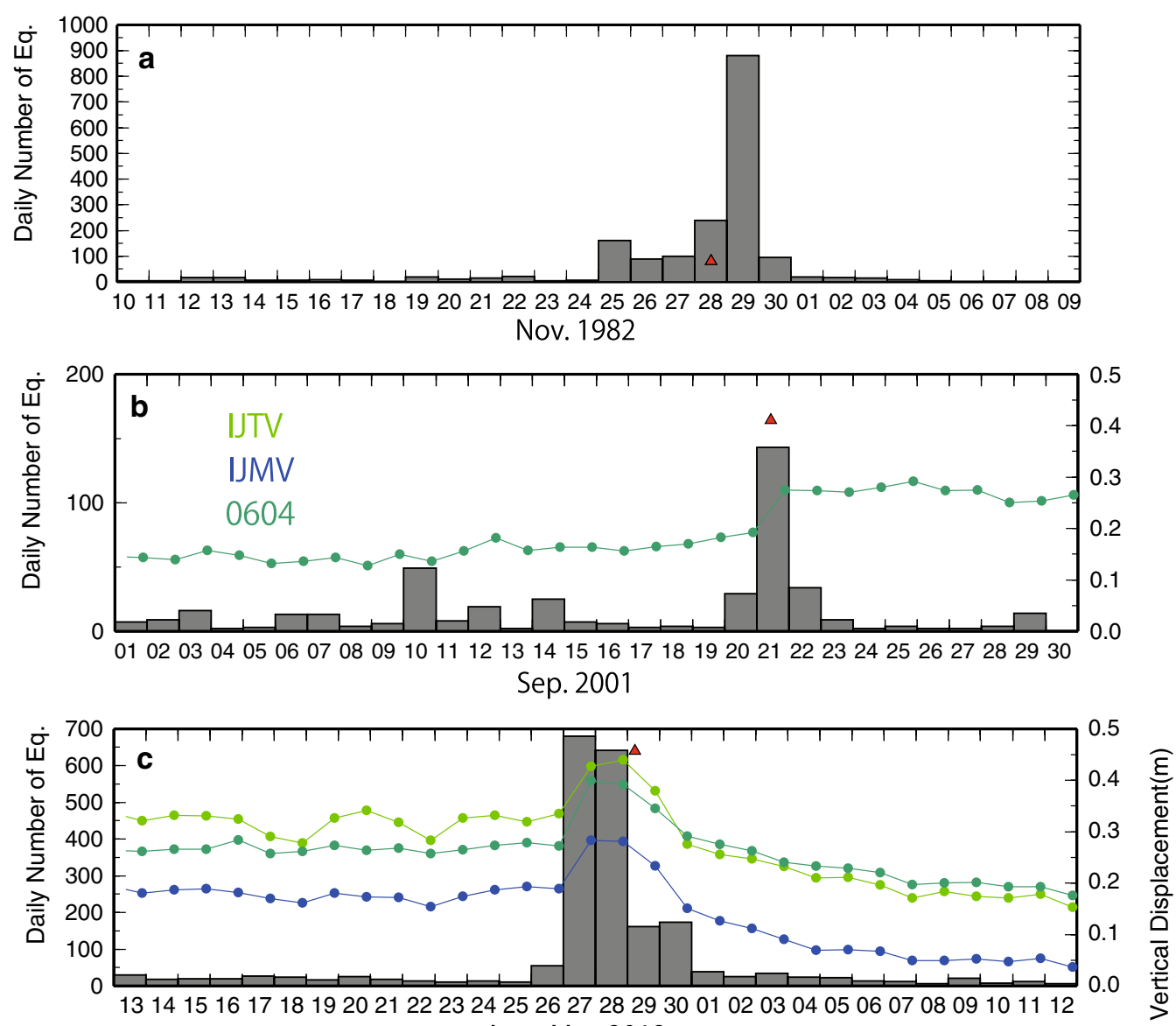
Apr. -May 2012

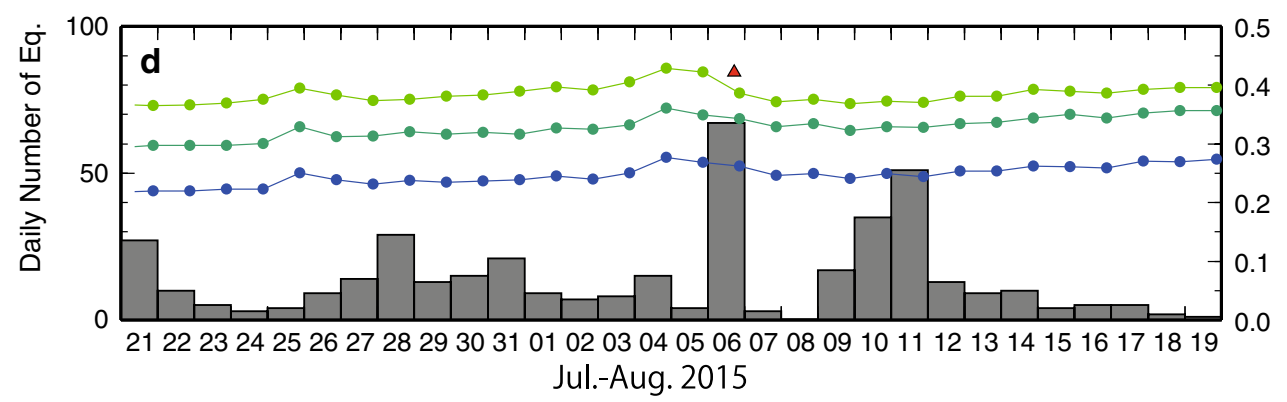

Fig. 4 The daily number of earthquakes and vertical movement at Motoyama before and after phreatic eruptions accompanied by precursors. a The eruption on November, 28-29, 1982; b the eruption on September 21, 2001; c the eruption on April 29, 2012; d the eruption on August 6, 2015. The green and blue curves denote vertical movement at GNSS observation stations. The red triangles denote the occurrence times of the eruptions, but the occurrence time of the eruption on November, 28-29, 1982 is not clear

stations sampled every $30 \mathrm{~s}$, the coordinates of each day were estimated by static analysis using GAMIT/GLOBK software. Motoyama uplifted during 2001-2003 and after 2006. The uplift was accelerated in 2011-2013. When the uplift rate is high, the number of earthquakes tends to be large; and earthquake activity is almost synchronized with the intermittent uplifts.

After the beginning of continuous observation of earthquakes in Ioto in March 1976, the eruptions of November
1982, September 2001, April 2012, and August 2015 were shown to be accompanied by seismic activity and crustal deformation (Fig. 4). From November 28-29, 1982, two phreatic eruptions took place at Asodai sinkhole. The times of these occurrences were not clear. During this period, the largest earthquake swarm occurred since the beginning of continuous observation in 1976, and 1492 earthquakes were observed from November 25-30 (Fig. 4a). Although continuous observation of the 
crustal deformation has not yet begun, Kumagai (1985) reported that many faults moved in the southern area, from Motoyama to Suribachiyama.

From around 20:00 on September 20 (Fig. 4b), about $14 \mathrm{~h}$ before the eruption on September 21, 2001, the number of earthquakes increased. At around 10:15 (Japan Standard Time) on September 21, 2001, white turbid discolored waters with a length of 300-400 m were spotted off the south of Ioto (No. 10 in Fig. 1c); sometimes, the sea water blows up by dozens of meters and white smoke rises to $100-300 \mathrm{~m}$. After the beginning of the eruption, continuous volcanic tremors were observed. Earthquake activity became quiet after vapor with a height of $100 \mathrm{~m}$ was spotted on the morning of September 22 (Japan Metrological Agency 2001). GNSS data from 1 week before and 1 week after the eruption show that station 0604 uplifted $10.6 \pm 0.5 \mathrm{~cm}$.

The number of earthquakes increased from April $27-28,2012$, and uplift of about $10 \mathrm{~cm}$ was observed at
Motoyama GNSS observation stations (Fig. 4c). From 4:30 on April 29, continuous volcanic tremors due to the eruption were observed. Since the eruption took place at nighttime, plume was not confirmed, but the explosion sounded. No evidence of magmatic eruption has been found. To see this in more detail, the seismometer amplitude is shown in Fig. 5a. This is a 10-min average of the root mean square amplitude of the vertical component seismometer at IJMV, and bandpass filters of $0.1-2 \mathrm{~Hz}$ are applied. Discolored water was confirmed off the northeast of Ioto from April 29-30 (Japan Metrological Agency 2013a). In a field survey conducted on May 24-25, we confirmed that the cliff on the coast of Tamehachi collapsed and an upwelling of discolored water off the coast of Tamehachi (No. 11 in Fig. 1c) occurred. Earthquake activity weakened after May 6. After the eruption of April 29, Motoyama had subsided by about $40 \mathrm{~cm}$ as of July 2012. Vertical displacement is superior to horizontal displacement, as shown in the next section.
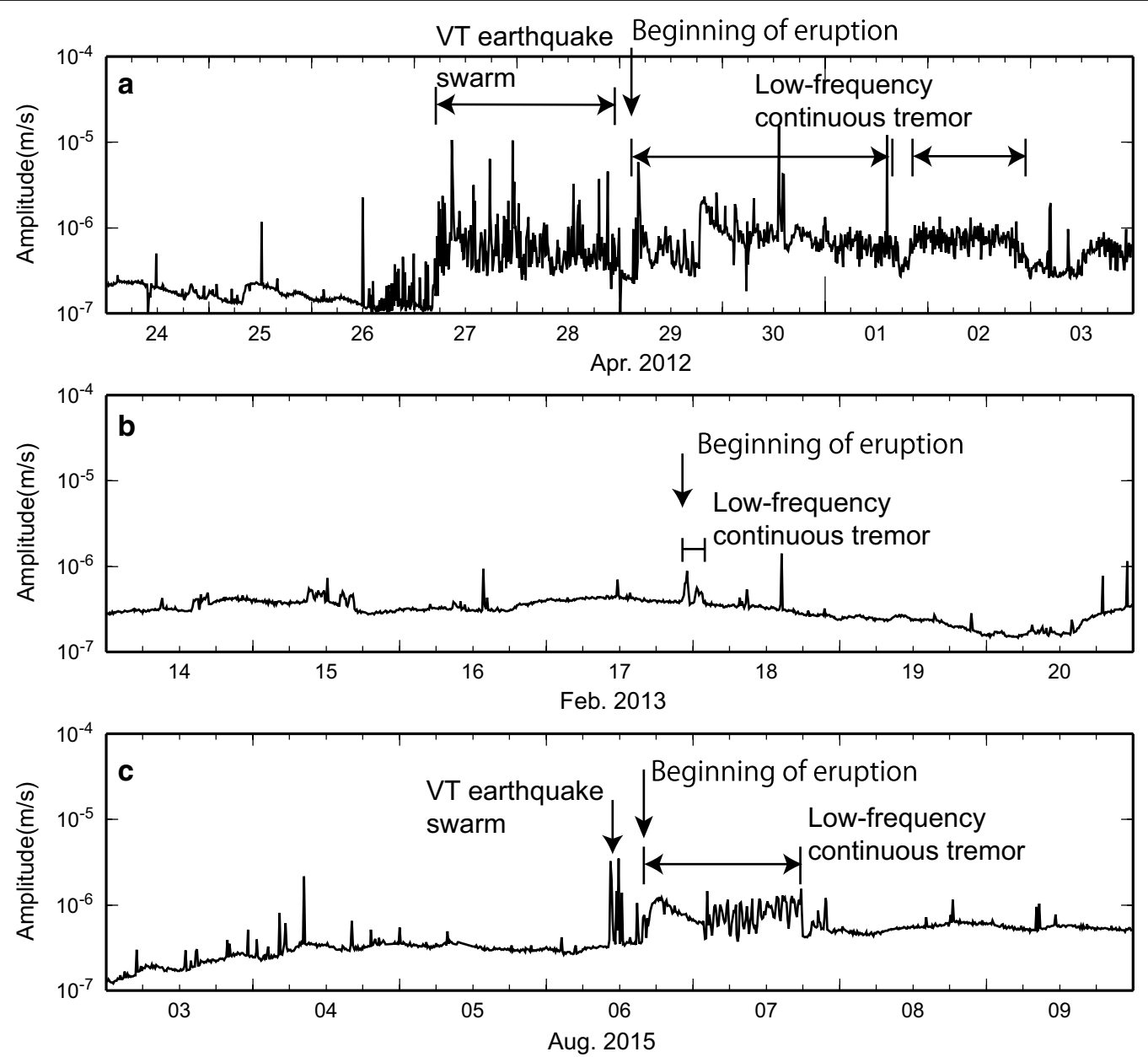

Fig. 5 The 10-min average of the root mean square amplitude of the seismometer at IJMV before and after the phreatic eruptions of a April 29, 2012; b February 17, 2013; and August 6, 2015. The seismometer data are vertical components and applied bandpass filters of 0.1-2 Hz 
Earthquake activity temporarily increased around 10:30 on August 6, 2015, and continuous volcanic tremors were observed from around 16:00 (Fig. 4d). To see this in more detail, the seismometer amplitude is shown in Fig. 5c. Continuous volcanic tremors were not observed on August 8. According to Japan Maritime Self-Defense Force, small eruptions intermittently occurred from around 2:43 on August 7 at Kitanohana (No. 3 in Fig. 1c). The height of the plume was about $100 \mathrm{~m}$. An uplift and a subsidence of about $2 \mathrm{~cm}$ were observed before the eruption.

On the other hand, there are eruptions without earthquake activity and crustal deformation. In an eruption that occurred on a beach at Idogahama (No. 8 in Fig. 1c) in March 1982, no increase in the earthquake count was observed despite ejecting lapilli up to $300 \mathrm{~m}$ (Fig. 6a). In an eruption that occurred at Idogahama in October 2001, a crater with a depth of about $50 \mathrm{~m}$ and a diameter of several tens of meters was formed. According to Japan Maritime Self-Defense Force, a lapillus of about $5 \mathrm{~cm}$ in diameter reached about $250 \mathrm{~m}$. We did not observe any activation of seismic activity or crustal deformation (Fig. 6b). A phreatic eruption that occurred in February 2013 at the Million Dollar hole ejected lapilli up to $220 \mathrm{~m}$, but we did not also observe any activation of seismic activity or crustal deformation (Fig. 6c). To see this in greater detail, the seismometer amplitude is shown in Fig. 5b. Several phreatic eruptions occurred at Million Dollar hole from 2012 to 2013, but none of them were accompanied by precursors. Seismic activity and crustal deformation related to other eruptions after 1976 are shown in Additional file 1: Figure S1 as an electronic supplement. In this paper, the precursor refers to the sharp increase in seismic activity and crustal deformation that are seen just before an eruption. In addition, one precursor corresponds to one eruption, and after the eruption its seismic activity and crustal deformation decrease. Intermittent uplift has occurred almost every 10 years, but the uplift does not correspond to each eruption and continues even after an eruption, so we do not call it a precursor here.
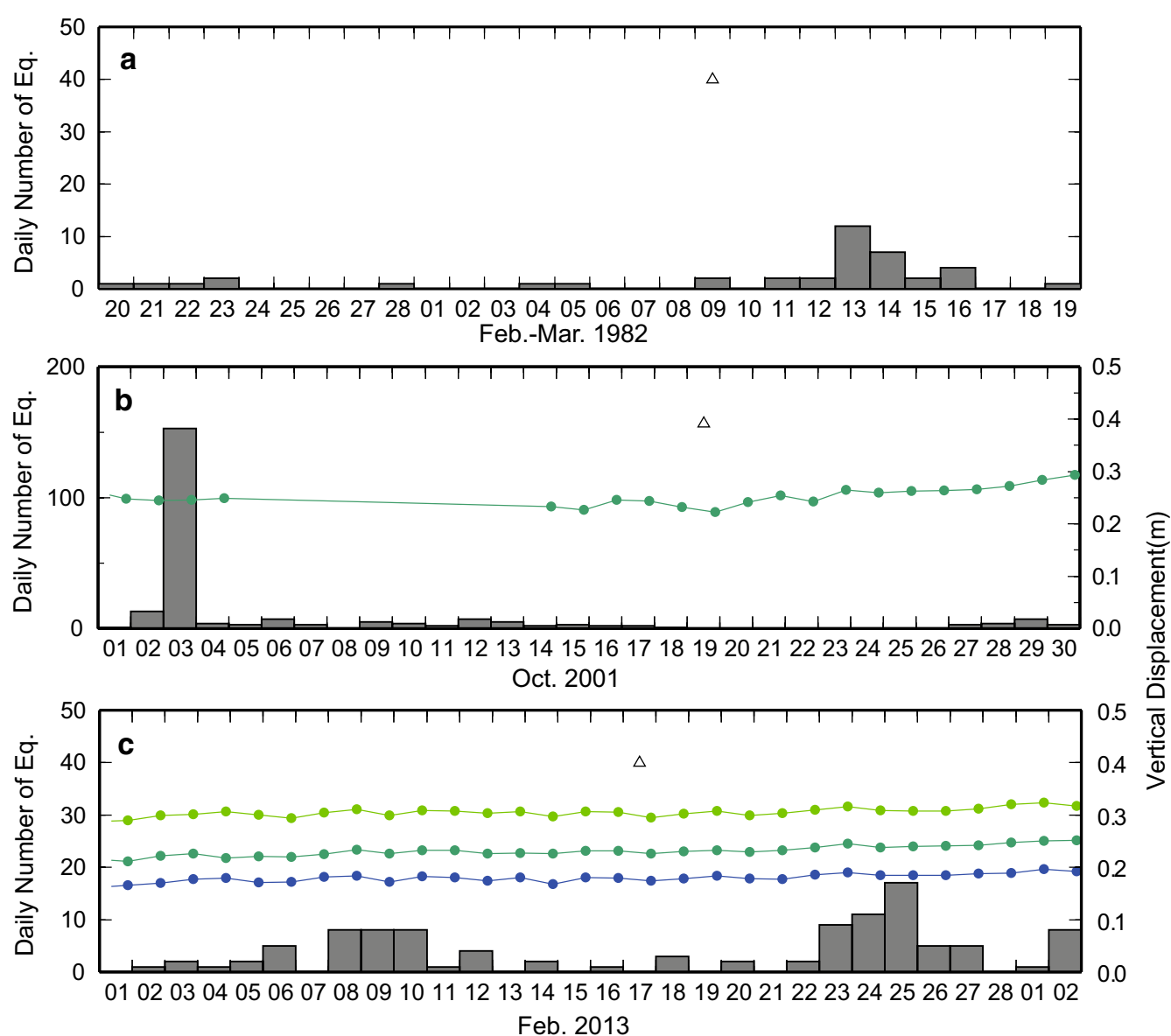

Fig. 6 The daily number of earthquakes and vertical movement at Motoyama before and after phreatic eruptions were not accompanied by precursors. a The eruption on March 9, 1982; b the eruption on October 19, 2001; c the eruption on February 17, 2013. The green and blue curves denote vertical movement at GNSS observation stations. The white triangles show the occurrence times of the eruptions 
Figures 2 and 3 show the occurrence times of four eruptions accompanied by precursors with red triangles, and the others with white triangles. All four eruptions accompanied by precursors occurred at a time when intermittent uplift occurred. Intermittent uplift and phreatic eruptions with precursors may have relevance, which will be discussed later.

\section{Data analysis}

\section{Modeling of geodetic data}

To elucidate the mechanisms of the occurrence of phreatic eruptions, we investigated the deformation source of crustal deformation observed before and after an eruption on the northern coast on April 29, 2012, which was the most obvious example of crustal deformation observed by GNSS observation. Figure 7 shows the horizontal and vertical displacement vectors before and after the beginning of the eruption with red arrows. The displacement before the eruption was calculated from the difference between April 27-28 and March 26-April 26 levels, and the displacement after the eruption was calculated from the difference between April 27-28 and July 1-31 levels. These displacements were referenced to 0603 station on Hahajima Island (see Fig. 1a). The horizontal vectors after the eruption point to the center of Motoyama. The vertical displacement was shown to be greater than the horizontal displacement. In addition, the displacement of Motoyama was greater than that of Suribachiyama. The deformation suggests that the deformation source is shallow and sill-like.

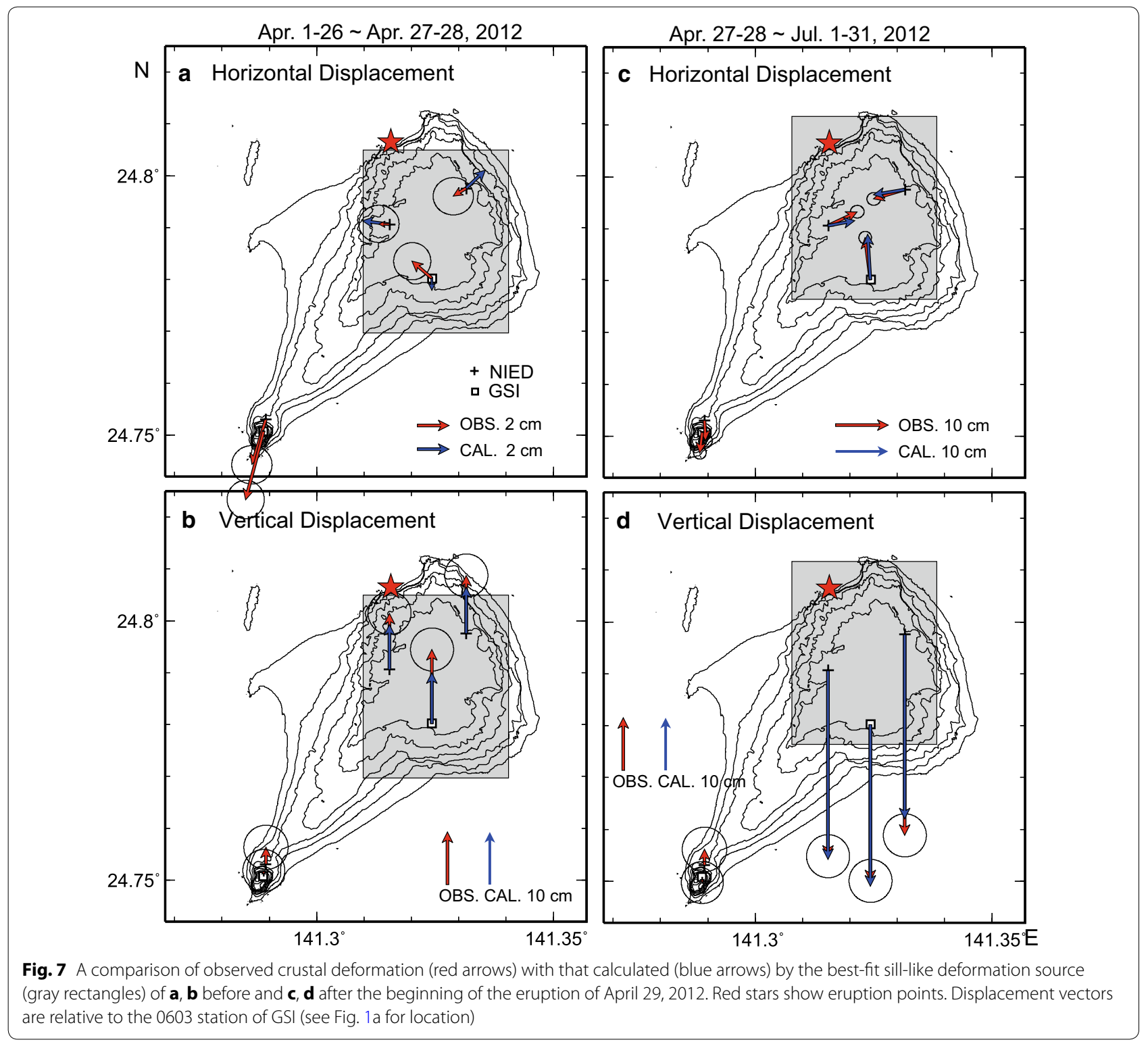


Assuming that the deformation source is a sill (Okada 1992), we estimated the best-fit parameter of the location of the center of the sill, size, and opening/closing amounts by using a method based on a genetic algorithm (Ueda et al. 2005) for the crustal deformation after the eruption where larger movements are observed. Furthermore, assuming that the depth and size of the source do not change before and after the beginning of the eruption, we estimated the location of the center of the sill and the opening/closing amounts for the crustal deformation before the eruption. Gray rectangles in Fig. 7 show the estimated sill source.

Our results show that the observed crustal deformation can be explained by best-fit parameters. Blue arrows in Fig. 7 show the calculated displacements by the best fit sill source. The best-fit parameters of sill source for after the eruption are depth $800 \mathrm{~m}$, size $3.0 \mathrm{~km} \times 3.9 \mathrm{~km}$, and closing amount $40 \mathrm{~cm}$. The $95 \%$ confidence intervals of the parameters are $500-1300 \mathrm{~m}, 8.7-17 \mathrm{~km}^{2}$, and $36-49 \mathrm{~cm}$, respectively. The $95 \%$ confidence intervals were estimated by adding observation noise to the observation data and inverting repeatedly. There is a tradeoff between depth and closing amount. The estimated opening amount before eruption is $11 \mathrm{~cm}$. The confidence interval is the range of the variation of the optimum value due to the observation noise. Motoyama is covered with porous pyroclastic flow deposits and is probably saturated with water as it is close to the sea. Therefore, the deformation may be affected by a poroelastic effect. In addition, there is a possibility that it may be affected by an inelastic effect, such as for active faults, as the distance between the observation station and the deformation source is very close. Figure 8 shows the relationship between the optimum value of the depth and the residual sum of squares. Although we assume elastic bodies and it is difficult to estimate the inelastic effect, we reckon that it is shallower than $2 \mathrm{~km}$. On the other hand, the result of assuming the Mogi model (Mogi 1958) as the deformation source after the beginning of an eruption is shown in Additional file 2: Figure S2 as an electronic supplement. In the case of the Mogi model, the source is located at the center of Motoyama $2.2 \mathrm{~km}$ deep and cannot explain the outstanding vertical displacement compared to horizontal displacement. Analysis results of crustal deformation before and after the eruption in August 2015 are shown in Additional file 3: Figure S3 as an electronic supplement. The analysis method is the same as was used for the April 2012 eruption, but the size of the sill before and after the eruption is not assumed to be the same. For the August 2015 eruption, crustal deformation with greater vertical displacement than horizontal displacement was observed and can be explained by a sill source of $860 \mathrm{~m}$ in depth.

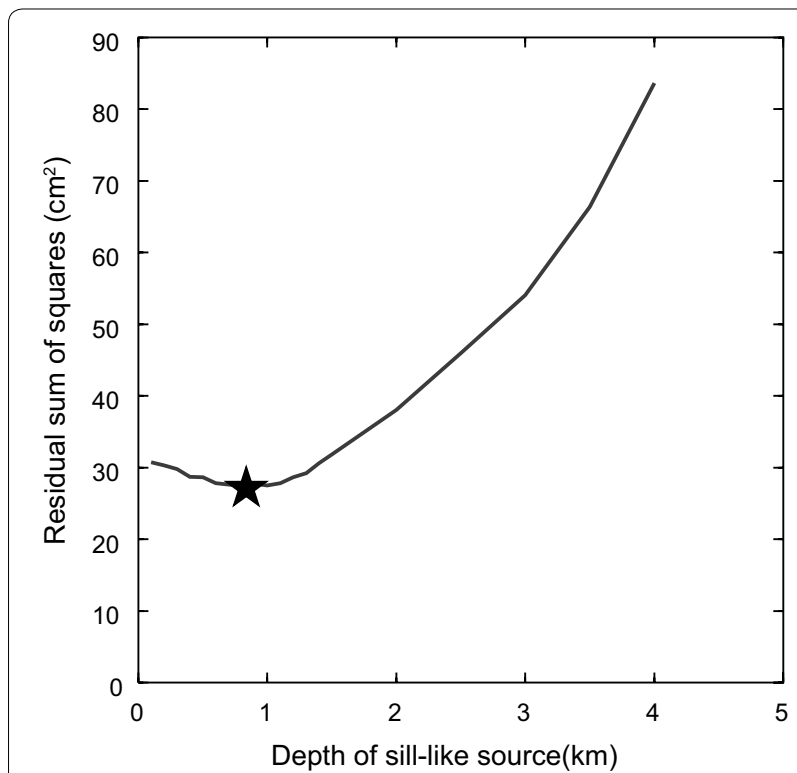

Fig. 8 The relationship between the optimum value of the depth and the residual sum of squares for crustal deformation after the beginning of the eruption on April 29, 2012. The star shows the optimum value of a depth of $800 \mathrm{~m}$ of the sill-like source. The curve shows the residual sum of squares at each depth

\section{Seismic array analysis}

The analysis of the crustal deformation data that was a precursor of the eruption showed that there is a sill-like pressure source at a shallow depth. However, the depth resolution is limited. In order to investigate the deformation source, we investigate the one-dimensional seismic velocity structure from the analysis of microtremors using a seismic array.

NIED conducted a seismic array observation with seven short-period seismometers at $300 \mathrm{~m}$ northwest of IJMV. The seismic array has been installed to monitor the incoming direction of volcanic tremors and to estimate the seismic velocity structure of shallow depths. The layout of the array is shown in Additional file 4: Figure S4 as an electronic supplement. The seismometers were installed at the vertex of an equilateral triangle with a side length of $170 \mathrm{~m}$, the midpoint of three sides, and the center. The sensors are vertical component seismometers with the natural period of $1 \mathrm{~Hz}$ (Sercel L-4), set at a depth of $50 \mathrm{~cm}$. We conducted continuous observation with a sampling frequency of $200 \mathrm{~Hz}$, and AD conversion is performed at 27 bits with the clock calibrated by GPS. Although it was installed as planned from December 2014 for 1 year to monitor volcanic tremors, the natural period changed in 1 week because of high ground temperatures, and some seismometers failed within half a month of installation. To estimate the underground structure, we used nighttime data and analyzed each of 
the 2 days to see the dispersion of the results in order to avoid artificial noise.

Figure 9 shows the one-dimensional velocity structure of the $\mathrm{S}$ wave estimated using microtremor observation for $3 \mathrm{~h}$ from 0:00 to 3:00 on December 6 and 12, 2014, and their average. A band-pass filter with a frequency of $0.1-20 \mathrm{~Hz}$ was applied, and the sampling frequency was resampled to $100 \mathrm{~Hz}$. We divided the record of $3 \mathrm{~h}$ every $163.84 \mathrm{~s}$ and calculated the spatial autocorrelation function. When we estimated the spatial autocorrelation function, a Parzen window with a bandwidth of $0.05 \mathrm{~Hz}$ was applied to the cross spectrum. From the spatial autocorrelation function, the phase velocity was estimated by employing the spatial autocorrelation method. The $S$ wave velocity structure was estimated from the phase velocity. Inverse analysis of the $\mathrm{S}$ wave velocity structure used a genetic algorithm employed by Yamanaka and Ishida (1995). Common to the results for 2 days, we can see a low-velocity layer at a depth shallower than $100 \mathrm{~m}$,

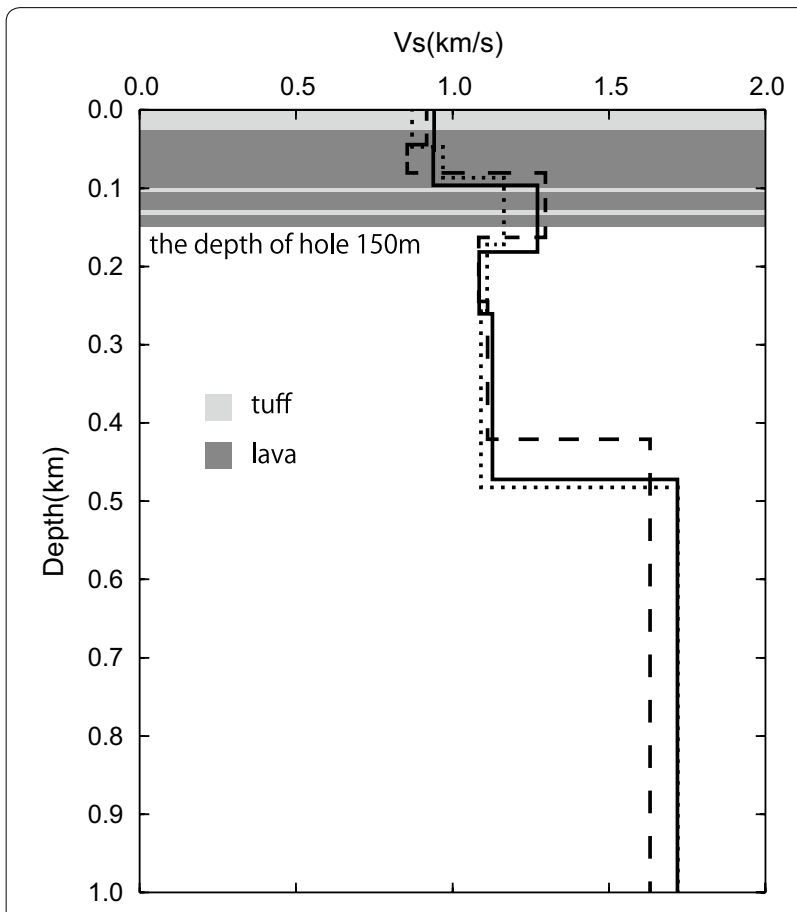

Fig. 9 The one-dimensional velocity structure of the S wave estimated using microtremor observation at the seismic array for $3 \mathrm{~h}$ from 0:00 to 3:00 on December 6 (dotted line) and 12 (broken line), 2014, and their average (solid line). The results of the analysis show that there is a low-velocity surface layer up to a depth of $100 \mathrm{~m}$, a high-velocity layer of $1.2-1.3 \mathrm{~km} / \mathrm{s}$ at a depth of 100-180 m, a low-velocity layer of $1.1 \mathrm{~km} / \mathrm{s}$ at a depth of $180-480 \mathrm{~m}$, and a high-velocity layer of $1.7 \mathrm{~km}$ at a depth of $480 \mathrm{~m}$ or more. The dark gray and light gray layers show lava and tuff layers obtained by the borehole survey of a depth of $150 \mathrm{~m}$. (Reproduced with permission from Ossaka et al. 1985) a high-velocity layer at $100-180 \mathrm{~m}$, a low-velocity layer at $180-480 \mathrm{~m}$, and a high-velocity layer at deeper layers.

\section{Discussion}

In this section, we discuss the mechanisms of phreatic eruptions on Ioto by using observed crustal deformation and seismic activity, the results of seismic array analysis, and other information. As a result of investigating the sources of crustal deformation before and after the eruption on the northern coast on April 29, 2012, it was found that it could be explained by an expansion and contraction of the shallow horizontal planar body beneath Motoyama. Because this planar body rapidly expanded before the phreatic eruption and contracted with the onset of the eruption, we consider here the possibility that the deformation is caused by inflation and deflation of an aquifer filled with hot water. Our results are consistent with Ukawa et al. (2006). They showed that the crustal deformation of Ioto from the survey results up to 2002 is due to a superposition of the episodic uplift of the whole island and continuous deformation of Motoyama. This continuous deformation is due to the contraction of the central part of Motoyama and the uplift of the surrounding area. The contraction of Motoyama is explained by a plate-like contraction source at a depth of $0.1-2.4 \mathrm{~km}$ in the central part of Motoyama. They interpreted it as a long-term movement of volcanic fluid. Our analytical results show a short-term fluctuation of the volcanic fluid at the shallow depth.

The results of the seismic array deployed on Motoyama show that there is a low-velocity surface layer up to a depth of $100 \mathrm{~m}$, a high-velocity layer of $1.2-1.3 \mathrm{~km} / \mathrm{s}$ at a depth of $100-180 \mathrm{~m}$, a low-velocity layer of $1.1 \mathrm{~km} / \mathrm{s}$ at $180-480 \mathrm{~m}$ and a high-velocity layer of $1.7 \mathrm{~km} / \mathrm{s}$ at a depth of $480 \mathrm{~m}$ or more. In the borehole survey (depth $150 \mathrm{~m}$ ) carried out near the northeast $900 \mathrm{~m}$ of the seismic array, alternating layers consisting of lava flows and pyroclastic rocks were found (Ossaka et al. 1985). The lava layers at depths of 24-97.9 and 106.6-130.5 m are presumed to be the Motoyama lava and Hanareiwa lava, respectively, which can be seen on the coast (Nagai and Kobayashi 2015). The area deeper than $135.2 \mathrm{~m}$ is also a lava layer (Ossaka et al. 1985). Both the location of the seismic array and the borehole are covered with the same Motoyama tuff on the ground (Nagai and Kobayashi 2015), which suggests that there is no large difference in the underground structure. Probably, the high-velocity layer found by the seismic array at a depth of $100-180 \mathrm{~m}$ is a layer of lava. The low-velocity layer beneath the high-velocity layer is thought to consist of thick tuff rocks due to an unknown previous calderaforming eruption. The high-velocity layer beneath the lowvelocity layer may correspond to high-density intruding 
rocks suggested by a high gravity anomaly at the center of Motoyama by Ehara (1985).

The low-velocity layer found at a depth of about 200$500 \mathrm{~m}$ is presumed to be a comparatively high permeability tuff. Although it is suggested that the depth of the contraction source from the crustal deformation is less than $2 \mathrm{~km}$, there is limited resolution that can be judged as coinciding with the low-velocity layer (depth 200$500 \mathrm{~m}$ ) suggested from the seismic array. In addition, the depth of the borehole is $150 \mathrm{~m}$; there is no information of the deeper strata. However, as the low seismic velocity layer suggests the presence of low density substances such as tuff and water, it is likely that hydrothermal reservoirs will be present at this depth. Therefore, an aquifer filled with hot water, as suggested by the crustal deformation data, is presumed to be present in this tuff layer. This aquifer was covered with a layer of lava with low permeability. A hydrothermal reservoir sealed in this manner is subject to lithostatic pressure and stably exists, even at relatively high temperatures and high pressure.

This result suggests that phreatic eruptions with precursors occur with the following mechanism (Fig. 10). The hydrothermal reservoir rapidly expanded due to boiling before the eruption. The rapid expansion and an increase in seismic activity before the eruption indicate that the existing stable high temperature hydrothermal fluid confined in the reservoir became unstable before boiling and expanding (Morgan et al. 2009). Partial pressure decreases due to crustal deformation by intermittent uplift, and seismic activity is the most probable mechanism of the abrupt boiling because large deformation and severe earthquake activity occur in the island during the intermittent uplift and the phreatic eruptions with intense precursors are observed only when intermittent uplift is occurring. The intermittent uplift is interpreted as a consequence of magma injections into a deep magma reservoir (Ukawa et al. 2006). The pressure increase in the deep magma reservoir may supply high temperature fluid to shallow hydrothermal reservoirs. Therefore, a partial boiling point exceeded by the supply of high temperature fluid from the deep magma reservoir is another probable mechanism of the abrupt boiling. An expansion of the horizontal planar hydrothermal reservoir will cause stress concentration at the tip of it, resulting in horizontal extension of the planar reservoir. This leads to further pressure reduction and boiling. After that, if the tip of the planar reservoir reaches an active fault or a crack, hot water is blown out from it and a phreatic eruption occurs. It is also consistent with phreatic eruptions occurring relatively often in places where there are many active faults in the surrounding area of Motoyama, and not in it covered with lava. With a phreatic eruption, the planar reservoir rapidly contracts. The hydrothermal reservoir already connected to the ground surface boils at a lower temperature than when sealed as only hydrostatic pressure is applied. Thus, further boiling is promoted. The planar reservoir expanded about $10 \mathrm{~cm}$ before the eruption on April 28, 2012, but shrank $40 \mathrm{~cm}$ after the

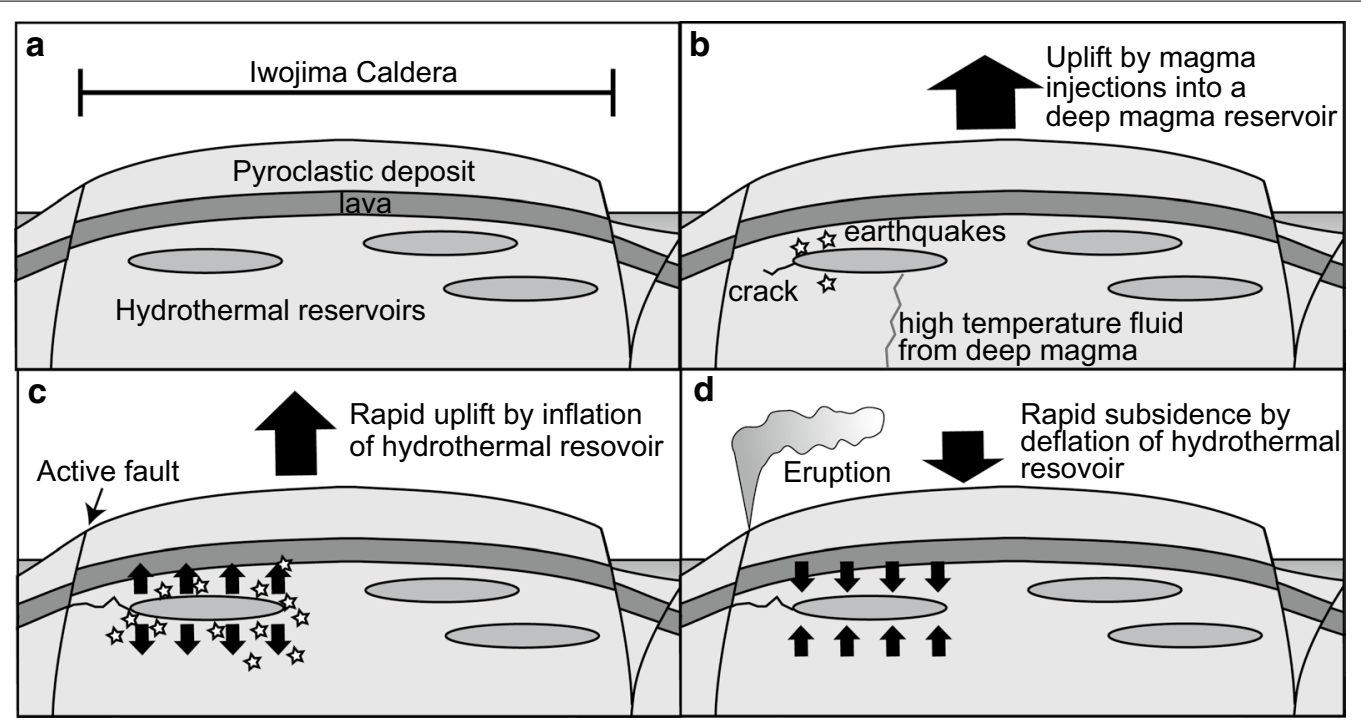

Fig. 10 A schematic illustration of an inferred mechanism of phreatic eruptions accompanied by precursors in loto. a Before the eruption, hydrothermal reservoirs were sealed beneath the lava layer and subjected to lithostatic pressure, and existing in a stable manner even at a relatively high temperature and high pressure. $\mathbf{b}$ Intermittent uplift and seismic activity cause a partial pressure decrease and a partial boiling point exceeded by supply of high temperature fluid from the deeper section due to a pressure increase in a magma chamber. c The horizontal planar hydrothermal reservoir inflates and leads to further pressure reduction and boiling. After that, if the tip of the planar reservoir hits an active fault or a crack, hot water is ejected and a phreatic eruption occurs. $\mathbf{d}$ After the beginning of the phreatic eruption, the planar hydrothermal reservoir rapidly contracts 
eruption (as of July 2012). If the pressure before and after the eruption of the reservoir is the same, the amount of inflation just before the eruption should be the same as the amount of deflation after the eruption. The larger amount of deflation after the eruption indicates that the pressure after the eruption is greatly lower than before the eruption. This indicates that the pressure inside the reservoir was lithostatic pressure before the eruption, but it decreased to hydrostatic pressure after the eruption. In the eruption of September 2001, subsidence of $4 \pm 0.4 \mathrm{~cm}$ was also observed until the middle of the following October (Fig. 6b). However, during this period, large-scale uplift occurred whereby subsidence is underestimated.

Phreatic eruptions that occur in Ioto mostly come without severe earthquake activity and crustal deformation. Such eruptions occurred at Idogahama and Million dollar hole, where eruptions took place many times in the past (Table 1). In the vicinity of the eruption of April 29, 2012, the occurrences of past eruptions were not recorded. In addition, the Asodai sinkhole, where an eruption occurred on November 28, 1982, was formed around 1971; and only small eruptions occurred in 1976 and 1978. There were no occurrences of eruptions accompanied by precursors after the 1982 eruption at the Asodai sinkhole. Therefore, the hydrothermal reservoirs related to eruptions without a precursor are probably weakly sealed compared to those related to eruptions with a precursor. In the latter case, the hydrothermal reservoirs are firmly sealed by the lava layer. On the other hand, in the former case, the hydrothermal reservoirs are connected to shallow depths, such as a sinkhole on the ground surface by previous eruptions. The plumbing connecting hydrothermal reservoirs and the shallow depths may be weakly sealed by clay generated through hydrothermal alteration of lava and tuff. If they are sealed with clay, the pressure of hydrothermal reservoirs does not become large, so it is presumed that no precursor seismic activity or crustal deformation will occur. Furthermore, in geothermal areas such as the Asodai sinkhole, which has already been made fumarolic, it is not sealed. If the ground surface and the hydrothermal reservoir are connected by thin plumbing, there is a possibility that phreatic eruptions may occur with the same mechanism as a geyser. A geyser is a hot spring characterized by intermittent discharge of water. The common prerequisite for geysers to exist is the availability of water and a supply of heat (e.g., Hurwitz and Manga 2017). Ioto, an island with high geothermal activity, fits this description. In such cases, a hollow in which steam is trapped is formed in a section of the hydrothermal reservoir. The pressure rises and extruded hot water filling the conduit causes an eruption (e.g., Belousov et al. 2013). In addition, when connected with the conduit through a very narrow crack, the hot water does not circulate, and the water in the hydrothermal reservoir can suppress boiling by hydrostatic pressure. When the water begins to boil, hydrostatic pressure decreases due to extrusion of water near the ground surface suddenly boiling and extruding the hot water filling the conduit (Rojstaczer et al. 2003). In both cases, it is presumed that there is no precursor phenomenon, such as crustal deformation or seismic activity, because hot water filling the conduit near the ground is pushed rather than the planar reservoir being pushed by a rise in pressure. In such craters, eruptions repeatedly occur as long as there is water and a heat source, and eruption may occur at any time regardless of an occurrence of an intermittent uplift.

A clear precursor before a phreatic eruption is a very useful signal to avoid damage. However, since hydrothermal reservoirs are distributed under Motoyama, it is difficult to estimate in advance where an eruption will occur even if we could observe precursors. Since the central area of Motoyama is covered with lava, the possibility of phreatic eruptions seems to be small. On the other hand, since the fracture is developed in the southwestern part of Ioto, where there are many active faults, phreatic eruption tends to occur. In order to avoid damage from this type of eruption, it is advisable not to approach active faults or coastal areas and retreat indoors if possible. On the other hand, phreatic eruptions without clear precursors are difficult to predict. However, since it is thought that this type of eruption is already connected with a hydrothermal reservoir and crater, it is better not to approach fumaroles or hot water pools. Also, it should be noted that even if it seems safe to approach, there is a high possibility that water near the surface of the ground will spring up just before an eruption. In such cases, you should evacuate immediately.

\section{Summary}

In Ioto, phreatic eruptions occur with intense seismic activity and crustal deformation beforehand as well as with no obvious precursors. After the beginning of continuous seismic observation in March 1976, four eruptions were shown to have precursors and 29 were shown to have none. The former are observed only during periods of repeated intermittent uplifts. In addition, crustal deformation before and after the four eruptions accompanied by precursors indicates that a sillshaped deformation source beneath the shallow part of Motoyama rapidly expands before an eruption and contracts with an eruption. An eruption accompanied by a precursor is thought to occur due to abrupt boiling of water in a hydrothermal reservoir in the tuff layer due to intermittent uplift. For the eruptions without precursors, the hydrothermal systems are weakly sealed by clay 
or probably occur on the same principle as a geyser, as phreatic eruptions occurred in the past and a crater on the ground surface and a hydrothermal reservoir were already connected. The results indicate that we can reduce the risk of damage due to phreatic eruptions without precursors by keeping a safe distance from craters where eruptions are likely to occur and phreatic eruptions with precursors by evacuating indoors when precursors are detected.

\section{Additional files}

Additional file 1: Figure S1. The daily number of earthquakes and vertical movement at Motoyama before and following phreatic eruptions after 1976 were not accompanied by precursors. The eruption list is shown in Table 1. The green and blue curves denote vertical movement at GNSS observation stations. The white triangles show the occurrence times of the eruptions.

Additional file 2: Figure S2. A comparison of observed crustal deformation (red arrows) with that calculated (blue arrows) by the best-fit Mogi model (red circle) of (a, b) after the beginning of the eruption of April 29, 2012. Red stars show eruption points. Displacement vectors are relative to the 0603 station of GSI (see Fig. 1a for location).

Additional file 3: Figure S3. A comparison of observed crustal deformation (red arrows) with that calculated (blue arrows) by the best-fit sill-like deformation source (gray rectangles) of $\mathbf{a}, \mathbf{b}$ before and $\mathbf{c}, \mathbf{d}$ after the beginning of the eruption of August 5, 2015. Red stars show eruption points. Displacement vectors are relative to the 0603 station of GSI (see Fig. 1a for location).

Additional file 4: Figure S4. The layout of the seismic array. Red triangles indicate where the seismometers are installed. Contour intervals of topography are $5 \mathrm{~m}$.

\section{Authors' contributions}

$\mathrm{HU}$ analyzed the data and created a draft. MN maintained the observation network of loto and cooperated in drafting the manuscript on the geological point. TT maintained the observation network of loto and cooperated in drafting the manuscript. All authors read and approved the final manuscript.

\section{Acknowledgements}

We would like to thank the JSDF, which supported the research at loto for an extended period. Furthermore, we appreciated review comments from Dr. Mike Poland and Dr. Halldór Geirsson, which greatly improved this manuscript. We also thank Geospatial Information Authority of Japan for providing us with GNSS data from GEONET and DEM data for the loto volcano.

\section{Competing interests}

The authors declare that they have no competing interests.

\section{Ethics approval and consent to participate}

Not applicable.

\section{Publisher's Note}

Springer Nature remains neutral with regard to jurisdictional claims in published maps and institutional affiliations.

Received: 18 December 2017 Accepted: 27 February 2018

Published online: 12 March 2018

\section{References}

Bellucci F, Woo J, Kilburn C, Rolandi G (2006) Ground deformation at Campi Flegrei, Italy: implications for hazard assessment. In: Troise C, De Natale G, Kilburn C (eds) Mechanisms of activity and unrest at large calderas, Special Publications, vol 269. Geol. Soc., London, pp 141-157. https://doi. org/10.1144/gsl.sp.2006.269.01.09

Belousov A, Belousova M, Nechayev A (2013) Video observations inside conduits of erupting geysers in Kamchatka, Russia, and their geological framework: implications for the geyser mechanism. Geology 41(4):387390. https://doi.org/10.1130/G33366.1

Chang WL, Smith RB, Wicks C, Farrell J, Puskas CM (2007) Accelerated uplift and magmatic intrusion of the Yellowstone caldera 2004-2006. Science 318(5852):952-956. https://doi.org/10.1126/science.1146842

Corwin G, Foster HL (1959) The 1957 explosive eruption on Iwo jima, Volcano Islands. Am J Sci 257:161-171

Ehara S (1985) Gravity anomalies on Iwo-jima. J Geogr (Chigaku Zasshi) 94-6:488-497. https://doi.org/10.5026/jgeography.94.488 (in Japanese with English abstract)

Hurwitz S, Manga M (2017) The fascinating and complex dynamics of geyser eruptions. Annu Rev Earth Planet Sci 45:31-59. https://doi.org/10.1146/ annurev-earth-063016-015605

Japan Meteorological Agency (2001) Monthly Volcanic Activity Report (September 2001) http://www.data.jma.go.jp/svd/eqev/data/gaikyo/ monthly/200109/monthly200109.pdf. Accessed 23 Aug 2017 (in Japanese)

Japan Meteorological Agency (2012) Monthly Volcanic Activity Report (December 2012) http://www.data.jma.go.jp/svd/vois/data/tokyo/eng/ volcano_activity/2012/2012_12_monthly.pdf. Accessed 23 Aug 2017 (in Japanese)

Japan Metrological Agency (2013a) National Catalogue of the Active Volcanoes in Japan (fourth edition, English version)

Japan Meteorological Agency (2013b) Monthly Volcanic Activity Report (February 2013) http://www.data.jma.go.jp/svd/vois/data/tokyo/eng/ volcano_activity/2013/2013_02_monthly.pdf. Accessed 23 Aug 2017 (in Japanese)

Japan Meteorological Agency (2013c) Monthly Volcanic Activity Report (March 2013) http://www.data.jma.go.jp/svd/vois/data/tokyo/eng/ volcano_activity/2013/2013_03_monthly.pdf. Accessed 23 Aug 2017 (in Japanese)

Japan Meteorological Agency (2013d) Monthly Volcanic Activity Report (April 2013) http://www.data.jma.go.jp/svd/vois/data/tokyo/eng/volcano_activity/2013/2013_04_monthly.pdf. Accessed 23 Aug 2017 (in Japanese)

Japan Meteorological Agency (2013e) Monthly Volcanic Activity Report (August 2013) http://www.data.jma.go.jp/svd/vois/data/tokyo/eng/ volcano_activity/2013/2013_08_monthly.pdf. Accessed 23 Aug 2017 (in Japanese)

Japan Meteorological Agency (2014) Monthly Volcanic Activity Report (December 2014) http://www.data.jma.go.jp/svd/vois/data/tokyo/eng/ volcano_activity/2014/2014_12_monthly.pdf. Accessed 23 Aug 2017 (in Japanese)

Japan Meteorological Agency (2015a) Monthly Volcanic Activity Report (May 2015) http://www.data.jma.go.jp/svd/vois/data/tokyo/eng/volcano_activity/2015/2015_05_monthly.pdf. Accessed 23 Aug 2017 (in Japanese)

Japan Meteorological Agency (2015b) Monthly Volcanic Activity Report (June 2015) http://www.data.jma.go.jp/svd/vois/data/tokyo/eng/volcano_activity/2015/2015_06_monthly.pdf. Accessed 23 Aug 2017 (in Japanese)

Japan Meteorological Agency (2015c) Monthly Volcanic Activity Report (August 2015) http://www.data.jma.go.jp/svd/vois/data/tokyo/eng/ volcano_activity/2015/2015_08_monthly.pdf. Accessed 23 Aug 2017 (in Japanese)

Japan Meteorological Agency (2015d) Monthly Volcanic Activity Report (September 2016) http://www.data.jma.go.jp/svd/vois/data/tokyo/eng/ volcano_activity/2016/2016_09_monthly.pdf. Accessed 23 Aug 2017 (in Japanese)

Kaizuka S, Miyauchi T, Nagaoka S (1983) Marine terraces, active faults and tectonic history of Iwo-jima. Ogasawara Res 9:13-45 (in Japanese with English abstract) 
Kaizuka S, Kato S, Nagaoka S, Miyauchi T (1985) Geomorphology of Iwo-jima and surrounding sea floor. J Geogr (Chigaku Zasshi) 94-6:424-436. https://doi.org/10.5026/jgeography.94.424 (in Japanese with English abstract)

Kaneshima S, Kawakatsu H, Matsubayashi H, Sudo Y, Tsutsui T, Ohminato T, Ito H, Uhira K, Yamasato H, Oikawa J, Takeo M, lidaka T (1996) Mechanism of phreatic eruptions at Aso volcano inferred from near-field broadband seismic observations. Science 273(5275):642-645. https://doi. org/10.1126/science.273.5275.642

King J (1785) A voyage to the Pacific Ocean. Volume III, 2nd edn. London Kumagai T (1985) Volcanism and seismicity in the Iwo-jima volcanoes. Geogr (Chigaku Zasshi) 94-6:455-463. https://doi.org/10.5026/jgeography.94.455 (in Japanese with English abstract)

Mogi K (1958) Relations between the eruptions of various volcanoes and the deformations of the ground surface around them. Bull Earthq Res Inst Univ Tokyo 36:99-134

Morgan LA, Shanks WC III, Pierce KL (2009) Hydrothermal processes above the Yellowstone magma chamber: Large hydrothermal systems and large hydrothermal explosions. Geological Society of America, Boulder. https:// doi.org/10.1130/2009.2459

Morimoto R, Ossaka J, Hatori T, Izutsuya S, Urabe K, Takahashi H, Okada Y, Hirabayashi J, Isa K, Isobe H (1968) The upheaval of an insular volcano Iwo-jima, Ogasawara Islands and its recent state of activity. J Geogr (Chigaku Zasshi) 77(5):255-283. https://doi.org/10.5026/jgeography.77.5_255 (in Japanese with English abstract)

Nagai M, Kobayashi T (2015) Volcanic history of Ogasawara loto (Iwo-jima), Izu-Bonin Arc, Japan. J Geogr (Chigaku Zasshi) 124-1:65-99. https://doi. org/10.5026/jgeography.124.65 (in Japanese with English abstract)

Newhall CG, Dzurisin D (1988) Historical unrest at large calderas of the world. United States Geological Survey Bulletin 1855

NIED (1992) Volcano phenomenon investigation report of Ogasawara Iwojima (23rd report). National Research Institute for Earth Science and Disaster Prevention (in Japanese)

Ogawa T (1912) Ogasawara Island academic travel journal. J Geogr (Chigaku Zasshi) 24(12):835-845. https://doi.org/10.5026/jgeography.24.835 (in Japanese; original title translated)
Okada Y (1992) Internal deformation due to shear and tensile faults in a halfspace. Bull Seismol Soc Am 82:1018-1040

Ossaka J, Ozawa T, Hirabayashi J (1985) Survey of trial hole on Iwo-jima. J Geogr (Chigaku Zasshi) 94-6:445-454. https://doi.org/10.5026/jgeography. 94.445 (in Japanese with English abstract)

Oyagi N, Inokuchi T (1985) Geology of Iwo-jima. J Geogr (Chigaku Zasshi) 94-6:436-445. https://doi.org/10.5026/jgeography.94.436 (in Japanese with English abstract)

Robertson RM, Kilburn CRJ (2016) Deformation regime and long-term precursors to eruption at large calderas: Rabaul, Papua New Guinea. Earth Planet Sci Lett 438-15:86-94. https://doi.org/10.1016/j.epsl.2016.01.003

Rojstaczer S, Galloway DL, Ingebritsen SE, Rubin DM (2003) Variability in geyser eruptive timing and its causes: Yellowstone National Park. Geophys Res Lett. https://doi.org/10.1029/2003GL017853

Toyoshima K (1932) On geothermal activity of Iwo-jima. J Geogr (Chigaku Zasshi) 44(10):528-541. https://doi.org/10.5026/jgeography.44.528 (in Japanese; original title translated)

Tsuji S Kuriyama M, Tsurumi E (1969) Report on the research of Ogasawara islands. Report of Geographical Survey Institute (Japan) 37:1-18 (in Japanese)

Ueda H, Fujita E, Ukawa M, Yamamoto E, Irwan M, Kimata F (2005) Magma intrusion and discharge process at the initial stage of the 2000 Miyakejima activity inferred from tilt and GPS data. Geophys J Int. https://doi. org/10.1111/j.1365-246X.2005.02602.x

Ukawa M, Fujita E, Kobayashi T (2002) Recent volcanic activity of loto and the eruption in 2001. Ghikyu Mon 39:157-164 (in Japanese; original title translated)

Ukawa M, Fujita E, Ueda H, Kumagai T, Nakajima H (2006) Long-term geodetic measurements of large scale deformation at Iwo-jima caldera. Jpn J Volcanol Geotherm Res 150:98-118. https://doi.org/10.1016/j. jvolgeores.2005.07.008

Yamanaka H, Ishida H (1995) Phase velocity inversion using genetic algorithms. J Struct Constr Eng 46:9-17 (in Japanese)

\section{Submit your manuscript to a SpringerOpen ${ }^{\circ}$ journal and benefit from:}

- Convenient online submission

- Rigorous peer review

- Open access: articles freely available online

- High visibility within the field

- Retaining the copyright to your article

Submit your next manuscript at $\boldsymbol{\nabla}$ springeropen.com 